Relato de Experiência

\title{
Processo de construçáo da identidade ocupacional materna interrompida pelo luto ${ }^{1}$
}

\author{
Process of construction of the maternal occupational identity interrupted \\ by the grief
}

\author{
Danusa Menegat $^{\mathrm{a}}$ (D), Daniel Ferreira Dahdah ${ }^{\mathrm{a}}$ (D), Tatiana Barbieri Bombarda ${ }^{\mathrm{a}}$ (D), \\ Regina Helena Vitale Torkomian Joaquim ${ }^{a}$ (D) \\ ${ }^{a}$ Universidade Federal de São Carlos - UFSCar, São Carlos, SP, Brasil.
}

Como citar: Menegat, D., Dahdah, D. F., Bombarda, T. B., \& Joaquim, R. H. V. T. (2021). Processo de construçáo da identidade ocupacional materna interrompida pelo luto. Cadernos Brasileiros de Terapia Ocupacional, 29, e2134. https://doi.org/10.1590/2526-8910.ctoRE2134

\begin{abstract}
$\underline{\text { Resumo }}$
Este estudo objetivou investigar a ocupação de uma mulher que se tornou mãe de um bebê pré-termo, vivenciando, um mês após a alta hospitalar, o óbito do filho. Trata-se de um estudo qualitativo, cujo delineamento foi o Estudo de Caso, ancorado no referencial teórico do Modelo de Ocupação Humana. Os dados foram coletados por meio da aplicaçáo do instrumento Diário de Ocupaçôes (DO) e da realizaçáo de duas entrevistas semiestruturadas, uma delas realizada na Unidade de Cuidados Intermediários Neonatal e outra no contexto domiciliar. Os dados do DO foram organizados descritivamente e as entrevistas foram transcritas e, posteriormente, analisadas por meio da Análise de Conteúdo Temática. Observa-se que a construção da identidade ocupacional materna ocorreu de forma gradativa e relacionada à condição clínica do filho. Como categorias analíticas, emergiram dois temas: "Hospitalização do bebê pré-termo: um novo, desconhecido e amedrontador contexto para a futura e nova mãe" e "A morte e o processo de luto materno: como continuar a viver após o óbito do filho". Discute-se que se tornar mãe de um bebê pré-termo desvela mudanças na rotina que demanda a permanência em um ambiente hospitalar. Ademais, que a necessidade de enfrentar o luto se configurou como um novo e complexo desafio, uma vez que o processo da identidade materna foi interrompido ao vivenciar a perda inesperada do bebê. Pesquisas que abordem as ocupaçóes de mães de bebês pré-termos são relevantes para a prática da terapia ocupacional, pois permitem conhecer a construção da identidade materna no contexto do nascimento de risco, e, ainda, como lidar com o pesar associado ao luto materno.
\end{abstract}

Palavras-chave: Atividades Cotidianas, Maternidades, Recém-Nascido Prematuro, Luto, Terapia Ocupacional.

${ }^{1} \mathrm{O}$ artigo é parte da Tese de Doutorado, desenvolvida na Universidade Federal de São Carlos/ São Carlos - SP, intitulada “Ocupaçóes de mães de bebês pré-termos durante a internação e após a alta hospitalar”, de Danusa Menegat. Os procedimentos éticos vigentes foram cumpridos, a pesquisa foi aprovada pelo Comitê de Ética em Pesquisa em Seres Humanos da Universidade Federal de São Carlos (UFSCar), CAAE: 74765417.9.0000.5504 e número do parecer 2.457.585.

Recebido em Ago. 6, 2020; $1^{\text {a }}$ Revisão em Out. 7, 2020; 2a Revisão em Fev. 6, 2021; Aceito em Fev. 9,2021 


\begin{abstract}
$\underline{\text { Abstract }}$
This study aims to investigate the occupation of a woman who became the mother of a preterm baby, experiencing the child's death one month after hospital discharge. It is a qualitative study, whose outline was the Case Study, anchored in the theoretical framework of the Human Occupation Model. Data were collected through the application of the Daily Occupations (DO) instrument and two semistructured interviews, one conducted at the Neonatal Intermediate Care Unit and the other in the home context. The DO data were organized descriptively and the interviews were transcribed and subsequently analyzed using the Thematic Content Analysis. It is observed that the construction of maternal occupational identity occurred gradually and was related to the child's clinical condition. As analytical categories, two themes emerged: "Hospitalization of the preterm baby: a new, unknown and frightening context for the future and new mother" and "The death and the process of maternal mourning: how to continue to live after the child's death". It is argued that becoming a mother to a preterm baby reveals changes in the routine that demands staying in a hospital environment. Still, that the need to face the mourning was configured as a new and complex challenge since the maternal identity process was interrupted when experiencing the unexpected loss of the baby. Research that addresses the occupations of mothers of preterm babies is relevant to the practice of Occupational Therapy, as it allows knowing the construction of maternal identity in the context of risky birth, and also how to deal with the grief associated with maternal mourning.
\end{abstract}

Keywords: Activities of Daily Living, Maternity, Infant, Premature, Bereavement, Occupational Therapy.

\title{
Introduçáo
}

O termo "ocupação" é conceituado como um hábito ou papel composto por diversas atividades relacionadas a uma açáo ou comportamento (Kielhofner, 2008). Tal conceito é abordado no Modelo de Ocupação Humana ( $\mathrm{MOH})$, desenvolvido por Kielhofner, na década de 1970, e considera que cada indivíduo reage de maneiras distintas às situaçóes cotidianas. Assim, ressalta-se a importância de identificar as ocupaçóes consideradas significativas e satisfatórias para uma pessoa, além do contexto ambiental ao qual se insere (Kielhofner, 2011).

De acordo com o $\mathrm{MOH}$, o conceito de identidade ocupacional diz respeito a "quem a pessoa é" e "quem deseja se tornar como ser ocupacional" (Kielhofner, 2008). A identidade ocupacional é construída a partir de inúmeras características, como as açóes que os indivíduos sentem satisfação em realizar, os papéis sociais envolvidos e o que se espera de determinado papel (Taylor, 2017).

A construção da identidade de uma pessoa está estritamente relacionada ao desempenho de ocupaçóes vinculadas aos papéis ocupacionais. As relaçóes com outras pessoas e a necessidade intrínseca de satisfazer as expectativas sociais, impostas a determinado papel ocupacional, requer a adequação de comportamentos que satisfaçam tal exigência (Kielhofner, 2011). 
Ao tornar-se mãe, a mulher é impulsionada a realizar modificações nas ocupações a fim de responder às mudanças decorrentes da maternidade, as quais influenciarão na construção da identidade ocupacional materna (Martins, 2017). A maternidade como ocupação e as implicações de se tornar mãe de um bebê pré-termo, somadas ao contexto de internação do filho, geram uma repercussão significativa na vida da mulher, que abdica dos demais papéis ocupacionais para acompanhar o recém-nascido durante o período de hospitalização (Dittz et al., 2006; Melo et al., 2016).

O processo de construção da identidade materna é percebido como complexo e influenciado socialmente, sendo suscetível a mudanças e às ressignificaçóes vivenciadas pela mulher que se tornou mãe (Behar, 2018). De acordo com Stefana \& Lavelli (2017), ser mãe de um bebê pré-termo exige adaptação, pois a maternidade exercida durante a internação do filho poderá ser afetada pela separaçáo precoce, diminuição da possibilidade de contato pós-parto e pela necessidade de lidar com a condição de prematuridade.

Como referido também por Joaquim et al. (2018), mães de pré-termos apontam interações limitadas em razão da separação física e da falta de oportunidades plenas de contatos com o filho, manifestando sentimentos de ansiedade, culpa e insegurança para assumir o cuidado com o bebê. Além disso, a mãe convive constantemente com a iminência da morte e a incerteza da evolução clínica do bebê (Baseggio et al., 2017).

Quando ocorre a morte do bebê, sucede uma desconstrução da maternidade, ou seja, a perda da identidade materna. Nesse sentido, o óbito do filho poderá comprometer o comportamento da mãe, potencializando o sofrimento mental e impactando diversas esferas da vida. As mães, além de perder o filho, perdem a vida que planejaram com ele (Freitas \& Michel, 2014).

Apesar da complexidade do "constituir-se mãe de um bebê pré-termo" (Joaquim et al., 2018), pesquisas têm se dedicado à construção da identidade ocupacional materna, no entanto, há uma escassez de estudos que busquem compreender o impacto do luto pela morte do filho (Dahdah et al., 2019). Sendo assim, este estudo propóe pesquisar a ocupação de uma mulher que se tornou mãe de um bebê pré-termo em contexto hospitalar e, um mês após a alta, vivenciou o óbito do filho.

\section{Método}

Trata-se de um estudo de abordagem qualitativa, cujo delineamento foi o estudo de caso. O estudo de caso é considerado um método de pesquisa que investiga um fenômeno em profundidade e em seu contexto de mundo real (Yin, 2015). A abordagem qualitativa permite acercar-se dos significados, motivos, crenças e interpretaçôes relacionadas a como as pessoas vivem, sentem e pensam (Minayo, 2013).

O presente caso foi selecionado por apresentar uma oportunidade de pesquisar duas realidades complexas vivenciadas por uma mulher que se tornou mãe de um bebê prétermo e, um mês após a alta hospitalar, vivenciou o óbito do filho.

Os dados foram coletados durante o desenvolvimento de um estudo mais amplo, a saber, pesquisa de Doutorado da primeira autora, com mães de bebês pré-termos antes e após a alta hospitalar, submetido e aprovado pelo Comitê de Ética em Pesquisa em Seres Humanos da Universidade Federal de São Carlos (UFSCar), de acordo com a Resolução n. 466 do Conselho Nacional de Saúde (CNS) e assinatura do Termo de 
Consentimento Livre e Esclarecido (TCLE), sendo que a própria pesquisadora conduziu os procedimentos.

Para a coleta de dados, foram aplicados três instrumentos:

1 - Ficha de Identificaçáo (FI) - um dia após o primeiro contato da mãe com a pesquisadora, em UCIN, para a caracterização da díade mãe-bebê;

2 - Diário de Ocupaçóes (DO) - na primeira semana e na segunda semana de internação na UCIN. O instrumento foi adaptado e baseado no estudo de Martins (2017). A mãe era orientada a registrar livremente o preenchimento do DO em dois dias típicos da semana e no sábado, organizados em intervalos de tempo de duas em duas horas;

3 - Entrevista Semiestruturada (ES) - realizada após a aplicação do DO, a fim de aprofundar as atividades consideradas significativas e satisfatórias, na percepção da mãe. Este instrumento foi elaborado pelos pesquisadores a partir dos conceitos do Modelo de Ocupação Humana (MOH): Volição, Habituação, Capacidade de desempenho e Ambiente (Kielhofner, 2011).

A coleta de dados ocorreu do seguinte modo (Figura 1):

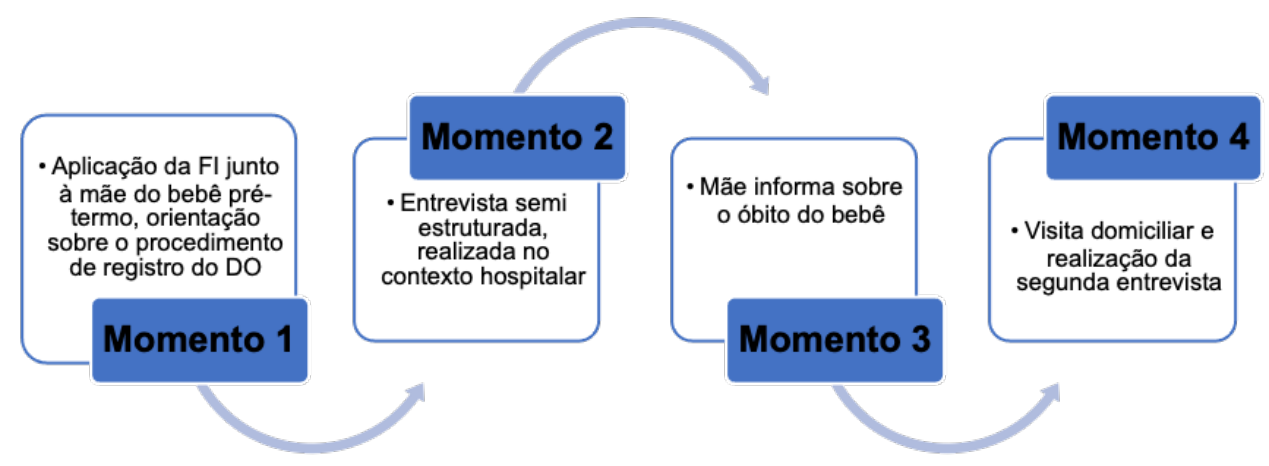

Figura 1. Procedimento de coleta de dados. Fonte: Os autores.

Para a análise, os dados do DO foram analisados de maneira descritiva. Os dados obtidos nas entrevistas foram gravados e transcritos na íntegra para posterior análise por meio da Análise de Conteúdo Temática. A técnica de análise permite descrever, de maneira objetiva e sistemática, o conteúdo refletido na transcrição (Minayo, 2013).

\section{Resultado}

Participou do estudo uma mãe com 21 anos de idade, em união estável há três anos. Possuía Ensino Médio completo e trabalhava como caixa de um supermercado, mas, no momento, estava em licença maternidade. A mãe não planejou a gravidez, referindo desejo de ter se programado para o primeiro filho, associando esse desejo a uma melhor estabilidade de sua condição socioeconômica.

O parto foi do tipo cesáreo, devido à pré-eclâmpsia materna grave. 
Seu bebê, de sexo masculino, nasceu pré-termo, com idade gestacional de 27 semanas e peso ao nascer de 950 gramas; e permaneceu internado durante 14 dias na Unidade de Cuidados Intermediários Neonatal (UCIN).

\section{Atividades realizadas durante a internaçáo do bebê registradas no DO}

A mãe registrou no DO os momentos em que se dedicou à ocupação de mãe, realizando os cuidados com o bebê enquanto estava no hospital. Aprender com a equipe foi ressaltado como ponto positivo no processo de tornar-se mãe, e também registrou as atividades "trocar a fralda" e "dar o banho", conforme relato: "O banho eu dei duas vezes porque atrasava o ônibus, ai não conseguia chegar mais cedo. Trocava a fralda, eu já sabia trocar porque troquei dos meus priminhos. Fralda foi a coisa mais simples”. Ressalta-se que a instituição seguia uma rotina pré-estabelecida de cuidados aos bebês, sendo que o banho era realizado no período matutino.

A amamentação, inicialmente, conforme procedimento do serviço, era realizada por gavagem (administração do leite da seringa pela sonda), evoluindo para "o uso da chuca" e alternando com o estímulo do seio materno. A mãe relatou que o bebê "cansava" ao esforçar-se para sugar a mama e que essa condição interferia no ganho de peso.

A mãe considerou a "amamentação" como uma atividade materna significativa nas duas semanas de internação do filho, conforme seu relato: "Amamentação ajuda no desenvolvimento da criança, ganha mais peso e tem mais nutrientes, o leite materno, nê".

$\mathrm{Na}$ última semana de internação, a mãe demonstrou alegria com a evolução clínica do filho associada à transferência da incubadora para o berço, em que poderia segurar o bebê com mais frequência, independência e autonomia; e à adaptação do bebê sem a necessidade de oxigênio, o que pode ser observado em sua fala: "Agora que ele está no berço eu pego ele mais, não preciso ficar chamando ela [técnica de enfermagem], ele também está se acostumando sem oxigênio". Com o bebê no berço, a mãe registra as atividades "segurar o bebê no colo" e "trocar de roupa" e as considerou satisfatórias ao desempenhálas. Conforme seu relato: "Fiquei feliz em ver o meu filho com a roupinha que a avó deu, eu deixei as roupinhas aqui já faz tempo, agora quando tem que trocar eu troco, isso que me deixa satisfeita".

Com o bebê no berço, atividades relacionadas à interação mãe-filho foram registradas no DO, como: "carinho na cabeça" e "conversar com o bebê", e essas foram percebidas como significativas nesse período.

No DO também foram registradas atividades domésticas, como "varrer a casa", "limpar a casa", "lavar a louça”, realizar a "limpeza do fogáo", "preparar o almoço" e "preparar a janta”. Como momento de lazer, em ambiente hospitalar, foi registrado “conversar com outras máes” e, em domicílio, "assistir televisão", atividade realizada no período noturno, em companhia com o marido.

Nos últimos dias de internação do bebê na UCIN, as atividades associadas à preparação para a alta do filho estiveram presentes no DO, como "organizar o armário do bebê", considerada significativa nesse período, conforme a fala: "Logo ele vai para a casa, eu preciso organizar o armário dele, tem muita roupinha que ganhei, as cobertas dele, mas falta comprar uma banheirinha, ai não vai faltar mais nada".

Das entrevistas, emergiram duas categorias temáticas: 


\section{Categoria 1 - Hospitalizaçáo do bebê pré-termo: um novo, desconhecido e amedrontador contexto para a futura e máe}

Esta categoria se refere à construção da identidade materna durante a internação do bebê pré-termo na UCIN. O período de internação do filho, logo após o nascimento, foi percebido pela mãe como um momento difícil. Ao receber alta da maternidade, e o bebê permanecer internado, relatou o sofrimento vivido no retorno ao domicílio, sem a presença física do bebê. Contou que essa situação interferiu na sua qualidade do sono, como se nota na fala:

Eu senti falta dele quando cheguei em casa, no hospital não senti muito, mas em casa eu chorei, tive pesadelos, mas quando acordo sei que ele está no berçário, que está tudo bem graças a Deus, ai eu durmo de novo, mas sempre estou preocupada.

As dificuldades financeiras a impossibilitava de acompanhar, diariamente, a internação do filho. Essa situação a incomodava e relatou que procurou ajuda de custo na instituição hospitalar, para utilizar o transporte público com mais frequência, porém, não obteve êxito, como relata:

Antes vinha à tarde porque conseguia carona com a ambulância, mas ficava pouco tempo com ele, então tentei ajuda no hospital para a passagem de ônibus, mas não consegui. Como preciso de dois onibus para ir ao hospital e mais dois para retornar, fico com ele do meio dia e meia até duas e meia, não consigo ficar mais e nem vir todos os dias.

A mãe relatou que profissional da equipe perguntou o motivo para não frequentar a unidade regularmente e contou que se sentiu desconfortável ao se explicar, como segue: "A moça [enfermeira] perguntou por que eu demorei, às vezes, fico quatro dias sem ver meu filho, e não posso aos finais de semana porque não tem ônibus, então, eu expliquei toda a situação para ela".

A mãe demonstrou preocupação pela situação de prematuridade do filho, assim, relata que participava de um grupo, na rede social Facebook, criado para o compartilhamento de experiências, particularmente, da maternidade na situação de prematuridade do filho. Segue seu relato:

Eu participo de um grupo no Facebook, eu leio as histórias das mães que também passam por isso, tinha uma mãe, o filho teve pneumonia, após o nascimento, e que também nasceu pré-termo. Algumas máes falam que têm medo de engravidar novamente, porque a gente tem medo mesmo.

Durante a internação na UCIN, a mãe relatou ser difícil ver o bebê na incubadora, necessitando de monitoração da saturação de oxigênio, conforme seu relato: " $E$ difícil ver ele na incubadora, fico olhando, não quero mexer muito, ele precisa ainda de oxigênio e tem muito "fio" nele".

Nos relatos, a mãe acreditava que só poderia segurar o filho no colo quando ele saísse da incubadora: "Eu achava que não poderia segurar ele porque nasceu prematuro e, por isso, achava que não poderia tirar ele da incubadora”. Na UCIN, a mãe referiu que solicitou 
ajuda para segurar o bebê, após observar outra mãe requerer auxílio à técnica de enfermagem.

A mãe descreveu as sensaçóes e percepçôes ao segurar o filho no colo pela primeira vez, assim: "Eu senti o frio do meu filho perto, só tinha sentido o cheiro dele quando ele nasceu [...] Ele já está bem "graudinho".

Com a expectativa da alta, a mãe foi informada da necessidade do bebê ser submetido a uma cirurgia, pois apresentava uma hérnia inguinal direita redutível desde o nascimento: "Achei que ele iria para a casa hoje. Ela [técnica de enfermagem] estava dando banho nele, ai ela explicou, disse que ele iria fazer a cirurgia e que pensava que as meninas [técnicas de enfermagem] haviam explicado". Referente a essa situação, o relato identifica a falha de comunicação da equipe perante a máe.

\section{Categoria 2 - A morte e o processo de luto materno: como continuar a viver após o óbito do filho}

A categoria explicita como ocorreu o óbito do filho, a vivência materna após a perda e a elaboraçáo do luto, permeada por sentimentos de culpa e sofrimento.

A mãe contou como ocorreu a morte do filho e a tentativa de salvá-lo, conforme seu relato:

Ele estava no meu colo, adormeci e fiquei com ele até meu marido voltar do trabalho. Não sei, acho que voltou o leite, só que eu demorei a perceber. Quando acordei, meu marido havia chegado, então, percebi que o bebê estava muito pálido, o chamamos, ai ele queria chorar só que não saia, ainda assoprei sua boca, porque, às vezes, com a respiração boca a boca o leite poderia voltar.

Ao perceber que o filho não reagia, dirigiram-se à Unidade de Pronto Atendimento (UPA). Após, o bebê foi encaminhado diretamente para a Unidade de Terapia Intensiva Neonatal (UTIN) e passou por alguns exames que identificaram a insuficiência respiratória. Inicialmente, a mãe relata que acreditava na pronta recuperação do filho, porém, após a transferência para a UTIN, percebeu a gravidade do estado do bebê, uma vez que retrocedem os sentimentos vivenciados durante a internação e a iminência da morte: "Chorou um pouco, então fiquei alegre, mas, quando falou que era necessário ser transferido para a UTIN... aí...”.

A mãe relatou como foi difícil lidar com a morte do filho, como segue a fala: "Eu e meu marido passamos na funerária para comprar o caixáo, levei a roupa dele. Aquele caixão tão pequenininho... cheguei em casa à meia noite, com os olhos inchados de tanto chorar, no outro dia de novo, chorar. Era dificil acreditar [...]". Conta que, nos primeiros dias após o óbito do bebê, adormecia com uma peça de roupa pertencente ao filho ou admirava alguma fotografia dele. "Demorei quase uma semana para dormir [...] as roupinhas que nem usei nele ainda estäo dobradinhas, as cobertas que ele usou também... Às vezes eu durmo com uma peça roupa, fico olhando as fotografias antes de dormir...", ela diz.

A vivência da perda do filho interferiu na organização das atividades domésticas: "Resolvi as coisas já, mas arrumar a casa... na verdade nem peguei totalmente, desde a última vez que a minha mãe veio me ajudar na limpeza, eu não faxino mais". 
Referente ao processo de luto, a mãe relatou assim: "Tem dias que tenho a sensação de que metade do coração foi embora". Também refere dificuldades em lidar com o sentimento de culpa: "Eu sei que eu posso ter errado mesmo, mas não é fácil perder um filho".

A sensação de culpa foi reforçada no ciclo de convivência do trabalho, pois a mãe presenciou comentários dos colegas que a culpavam pela morte do filho. A mãe contou que a consideraram omissa em relação aos cuidados para com o bebê, como refere: "Ouvi comentários no trabalho de que após amamentar eu havia deitado ele na cama, só que isso não aconteceu".

Em alguns momentos, a mãe demonstrava se sentir culpada pela morte do filho, mas também buscava na espiritualidade um meio de consolo:

Às vezes eu me sinto culpada, mesmo que Deus tenha levado ele, pode ter acabado a missão dele aqui. Às vezes, fico pensando no acontecido, se foi minha culpa, mas Deus sabe a hora, ele poderia estar aqui e passar por mais sofrimento. O médico disse que o leite poderia ir para o pulmão, então passaria por uma cirurgia, poderia ficar internado, acho que não iria aguentar não.

O envolvimento na ocupação de trabalho também foi percebido pela mãe de maneira positiva, externando a dificuldade de aceitação da perda, como percebesse na fala: "Comecei a trabalhar esses dias, conversar com as pessoas, no serviço ainda posso esquecer o que aconteceu, mas quando estou em casa eu lembro".

A mãe considerou que a primeira vivência da maternidade pode ter influenciado no cuidado com o filho pela dificuldade em identificar as necessidades do bebê: "Não sei se é porque sou mãe pela primeira vez, se eu pudesse voltar no tempo... porque se uma criança chora você não sabe se é fralda, se é leite, se é cólica".

Após a perda, a mãe referiu não compreender o significado de tornar-se mãe, demonstrando medo em vivenciar outra gestação e preocupando-se em satisfazer, da melhor forma, os cuidados ao bebê:

Ser máe, só vou entender quando eu engravidar novamente, o amor será em dobro, mas sempre irei lembrar que tive um filho e terei um cuidado maior. Fico preocupada que possa acontecer tudo de novo, às vezes, tenho medo, não da gravidez, mas depois do bebê nascer, irei lembrar o que aconteceu com ele [...].

Sentir falta do filho falecido, idealizá-lo vivo e reconhecer que uma segunda gestação seria acompanhada da lembrança da morte do primeiro bebê, aparecem no relato materno: "Eu vejo outras crianças e penso que poderia ser ele. Quando estava grávida, imaginava ele grandão, correndo [...] As pessoas ainda falam que vai passar, não passa, sempre irei lembrar dele, nunca vai ser um adeus e essa saudade dói”.

\section{Discussáo}

O estudo foi ancorado no marco teórico do Modelo de Ocupação Humana (MOH), transitando pelos conceitos de Volição, Habituação, Capacidade de Desempenho e Ambiente; a fim de investigar e conhecer a ocupação de uma mulher que se tornou mãe de um bebê pré-termo. 
Os resultados deste estudo apontaram o medo e a insegurança materna diante da prematuridade do filho, além de manifestar alteraçóes de sono e preocupação em se ausentar enquanto o bebê permanecia hospitalizado. Percebe-se que a Volição, elemento do $\mathrm{MOH}$, foi impactada de maneira negativa acerca da própria capacidade de engajamento e desempenho do papel materno (Lee \& Kielhofner, 2017a), em virtude da restrição imposta pelo Ambiente especializado e pelas condiçôes financeiras da mãe, que influenciaram na rotina de visitas diárias à Unidade, e que geraram questionamentos por parte dos profissionais.

A internação do filho é percebida pela mãe como difícil, devido às oscilaçôes da condição clínica. Esse contexto se configura como um desafio diário em lidar com a alternância do estado de saúde do bebê, de melhora à piora (Gibbs et al., 2016). Além disso, no elemento Habituação (Lee \& Kielhofner, 2017b), a mãe se esforça para conciliar outros papéis ocupacionais (do lar e esposa), externas ao ambiente hospitalar; além de organizar sua rotina.

Observa-se, nos relatos que, no decorrer da hospitalização, ocorreu o estabelecimento do contato mãe-filho e que esse interferiu positivamente na apropriação das ocupações desempenhadas e na construção da identidade materna. Melo et al. (2016) indicam que o envolvimento das máes no cuidado com o bebê se constitui como essencial para a construção da identidade materna.

Joaquim et al. (2018) consideram que a nova mãe inicia um período de aprendizagem na realização dos cuidados maternos e vivencia um processo de adaptação, antecipada pelo nascimento pré-termo. De acordo com Lee \& Kielhofner (2017a), a Volição é moldada com base nas experiências, caracterizadas como as oportunidades de aprendizado acerca do que fazer, além de permitir a descoberta daquilo que gosta de realizar.

Para Kielhofner (2011), a sensação de capacidade e eficácia (Volição) no desempenho de determinado papel se dará a partir da resolução das dificuldades percebidas durante a sua realização, para, então, adaptá-lo. Isso favorece a percepção de atividades como significativas e/ou satisfatórias.

Ao longo da internação, a mãe se sentiu satisfeita ao se envolver em atividades de cuidado, como "amamentar", "trocar a fralda" e "dar o banho". Fraga et al. (2019) identificaram que permitir o envolvimento materno no cuidado com o filho pré-termo possibilita a apropriação ao longo do tempo e, assim, as mães demonstram satisfação em exercê-las. A atuação do terapeuta ocupacional se mostra importante, visto que intervém no Ambiente, facilitando a participação da pessoa nas ocupaçôes diárias (Fisher et al., 2017).

$\mathrm{O}$ ato de amamentar foi considerado uma atividade significativa realizada pela mãe. Estudos mostram que o ato de amamentar está relacionado com o desenvolvimento da maternagem, em que ser capaz de amamentar é considerado importante para muitas mães, pois a progressão nessa ocupação desperta a sensação de ser mãe (Kronborg et al., 2015).

Após a morte do bebê, a mãe referiu não compreender o verdadeiro sentido de se tornar mãe, pois ocorreu a interrupção da construção da identidade como mãe. O luto materno é um fenômeno complexo, pois é visto como uma inversão no ciclo natural da vida e, apesar de se modificar com o tempo, à medida que a mãe encontra meios para lidar com a ausência do filho, é uma experiência jamais superada (Freitas \& Michel, 2014; Brice, 1991).

A mãe também relatou alterações na organização das atividades domésticas. O óbito do filho desestruturou o elemento Habituação, impactando negativamente na 
Capacidade de Desempenho do papel ocupacional materno e na manutenção da rotina habitual (Lee \& Kielhofner, 2017b).

A culpabilização materna também foi evidenciada no relato materno. Estudos relacionam o sentimento de culpa das mães com a sensação de fracasso na função materna, que a impossibilita de assegurar a vida do filho (Alarcão et al., 2008; Freitas \& Michel, 2014).

Quem falece continua presente nas lembranças, objetos, fotos e outras formas de presença (Forhan, 2010; Freitas, 2018). Para Taylor (2017), o Ambiente compóe os espaços ocupados, os objetos usados, a interação entre as pessoas, além dos significados existentes.

Como evidente neste estudo, Vidal (2010) e Muza et al. (2013) identificaram o medo materno em vivenciar uma nova gestação e reviver a perda do filho, visto o impacto que essa situação ocasiona na vida das mães. De acordo com Mendonça (2018), a terapia ocupacional busca estratégias que possam auxiliar e facilitar o envolvimento das pessoas nas ocupaçóes cotidianas, pois a perda do bebê pode impactar nas ocupaçóes desempenhadas pela mãe, bem como na elaboração do processo de luto.

\section{Conclusáo}

Os resultados deste estudo atenderam aos objetivos propostos, que permitiram pesquisar a ocupação de uma mulher que se tornou mãe de um bebê pré-termo, vivenciando, um mês após a alta hospitalar, o óbito do filho.

Apesar de restrito a um estudo de caso, a pesquisa ressalta a importância de conhecer a ocupação de uma mulher que se tornou mãe de um bebê em meio às situaçôes intimidantes que possam limitar o desempenho ocupacional, como é o caso do filho prétermo internado e a elaboração do luto materno. Fica clara a importância de pesquisas com enfoque na ocupação de mães de bebês pré-termos, sendo que, diante do que foi exposto, o Modelo de Ocupação Humana se constitui em uma abordagem teórica eficiente para estudos nessa ótica.

\section{Referências}

Alarcão, A. C. J., Carvalho, M. D. B., \& Pelloso, S. M. (2008). A morte de um filho jovem em circunstância violenta: compreendendo a vivência da mãe. Revista Latino-Americana de Enfermagem, 16(3), 341-347.

Baseggio, D. B., Dias, M. P. S., Brusque, S. R., Donelli, T. M. S., \& Mendes, P. (2017). Vivências de mães e bebês prematuros durante a internação neonatal. Temas em Psicologia, 25(1), 153-167. http://dx.doi.org/10.9788/TP2017.1-10.

Behar, R. C. R. (2018). A maternidade e seu impacto nos papéis ocupacionais de primiparas (Monografia). Universidade Federal da Paraíba, João Pessoa.

Brice, C. W. (1991). What forever means: an empirical existential-phenomenological investigation of maternal mourning. Journal of Phenomenological Psychology, 22(1), 16-38. http://dx.doi.org/10.1163/156916291X00028.

Dahdah, D. F., Bombarda, T. B., Frizzo, H. C. F., \& Joaquim, R. H. V. T. (2019). Revisão sistemática sobre luto e terapia ocupacional. Cadernos Brasileiros de Terapia Ocupacional, 27(1), 186-196. http://dx.doi.org/10.4322/2526-8910.ctoAR1079. 
Dittz, E. S., Melo, D. C. C., \& Pinheiro, Z. M. M. (2006). A terapia ocupacional no contexto da assistência à mãe e à família de recém-nascidos internados em unidade de terapia intensiva. Revista de Terapia Ocupacional da Universidade de São Paulo, 17(1), 42-47. https://doi.org/10.11606/issn.22386149.v17i1p42-47

Fisher, G., Parkinson, S., \& Haglund, L. (2017). The environment and human occupation. In R. Taylor (Ed.), Kielhofner's model of human occupation (pp. 91-106). Philadelphia: Wolters Kluwer Health/Lippincott Williams \& Wilkins.

Fraga, E., Dittz, E. S., \& Machado, L. G. (2019). A construção da co-ocupação materna na Unidade de Terapia Intensiva Neonatal. Cadernos Brasileiros de Terapia Ocupacional, 27(1), 92-104. http://dx.doi.org/10.4322/2526-8910.ctoAO1125.

Freitas, J. L. (2018). Luto, pathos e clínica: uma leitura fenomenológica. Psicologia USP, 29(1), 50-57. https://doi.org/10.1590/0103-656420160151

Freitas, J. L., \& Michel, L. H. F. (2014). A maior dor do mundo: o luto materno em uma perspectiva fenomenológica. Psicologia em Estudo, 10(2), 273-283. http://dx.doi.org/10.1590/1413737222324010.

Forhan, F. (2010). Doing, being, and becoming: a family's journey through perinatal loss. The American Journal of Occupational Therapy, 64(1), 142-151. http://dx.doi.org/10.5014/ajot.64.1.142.

Gibbs, D. P., Boshoff, K., \& Stanley, M. J. (2016). The acquisition of parenting occupations in neonatal intensive care: a preliminar perspective. Canadian Journal of Occupational Therapy, 83(2), 91-102. http://dx.doi.org/10.1177/0008417415625421.

Joaquim, R. H., Wernet, M., Leite, A., Fonseca, L., \& Mello, D. (2018). Interações entre mães e bebês prematuros: enfoque nas necessidades essenciais. Cadernos Brasileiros de Terapia Ocupacional, 26(3), 580-589. http://dx.doi.org/10.4322/2526-8910.ctoAO1051.

Kielhofner, G. (2011). Modelo de la ocupacion humana: teoría y aplicación. Espanha: Editoria Medica Panamericana.

Kielhofner, G. (2008). Model of human occupation: theory and application. Baltimore: Lippincott Williams \& Wilkins.

Kronborg, H., Harder, I., \& Hall, E. O. C. (2015). First time mothers'experiences of breastfeeding their newborn. Sexual \& Reproductive Healthcare : Official Journal of the Swedish Association of Midwives, 6(2), 82-87. http://dx.doi.org/10.1016/j.srhc.2014.08.004.

Lee, S. W., \& Kielhofner, G. (2017a). Volition. In R. Taylor (Ed.), Kielhofner's model of human occupation (pp. 38-56). Philadelphia: Wolters Kluwer Health/Lippincott Williams \& Wilkins.

Lee, S. W., \& Kielhofner, G. (2017b). Habituation: patterns of daily occupation. In R. Taylor (Ed.), Kielhofner's model of human occupation (pp. 57-73). Philadelphia: Wolters Kluwer Health/Lippincott Williams \& Wilkins.

Martins, S. (2017). Gravidez nas adolescências: construçōes das identidades ocupacionais maternas durante a gestação (Dissertação de mestrado). Universidade Federal de São Carlos, São Carlos.

Melo, R. A., Araújo, A. K. C., Marques, W. F., Santos, N. M., Fernandes, F. E. C. V., \& Bezerra, C. R. (2016). Sentimentos de mães de recém-nascidos internados em uma unidade de terapia intensiva neonatal. Revista Multidisciplinar e de Psicologia, 10(32), 88-103. http://dx.doi.org/10.14295/idonline.v10i32.569.

Mendonça, C. R. L. F. (2018). Sobre ocupar-se de cuidar do filho no hospital: o que dizem as mães de crianças cardiopatas? Revista de Terapia Ocupacional da Universidade de São Paulo, 29(3), 263-269. http://dx.doi.org/10.11606/issn.2238-6149.v29i3p263-269.

Minayo, M. C. S. (2013). O desafio do conhecimento: pesquisa qualitativa em saúde. São Paulo: Hucitec.

Muza, J. C., Sousa, E. N., Arrais, A. R., \& Iaconelli, V. (2013). Quando a morte visita a maternidade: atenção psicológica durante a perda perinatal. Psicologia: Teoria e Prática, 15(3), 34-48. 
Stefana, A., \& Lavelli, M. (2017). Parental engagement and early interactions with preterm infants during the stay in the neonatal intensive care unit: protocol of a mixed-method and longitudinal study. BMJ Open, 7(2), 1-7. http://dx.doi.org/10.1136/bmjopen-2016-013824.

Taylor, R. R. (2017). Kielhofner's model of human occupation: theory and application. Philadelphia: Wolters Kluwer.

Vidal, M. (2010). Gravidez após morte perinatal: sobre a relação da mãe com o bebê sobrevivente. Ciência \& Saúde Coletiva, 15(2), 3185-3190. http://dx.doi.org/10.1590/S1413-81232010000800023.

Yin, R. K. (2015). Estudo de caso: planejamento e métodos. Porto Alegre: Bookman.

\section{Contribuiçáo dos Autores}

Danusa Menegat e Daniel Ferreira Dahdah participaram do delineamento do estudo, análise e interpretação dos dados, da redação e da revisão crítica do manuscrito. Tatiana Barbieri Bombarda e Regina Helena Vitale Torkomian Joaquim participaram do delineamento do estudo, análise e interpretação dos dados, da redação e da revisão crítica do artigo. Todos os autores aprovaram a versão final do texto.

\section{Fonte de Financiamento}

CAPES - Coordenação de Aperfeiçoamento de Pessoal de Nível Superior - Código 001.

\section{Autor para correspondência}

Danusa Menegat

e-mail: danusamenegat@hotmail.com

\section{Editor de seçáo}

Prof. Dr. Milton Carlos Mariotti 